\title{
Correspondence
}

\section{Active expiration or synchrony?}

Sir,

I read with interest the paper of Field $e a^{1}$ and the ensuing correspondence regarding attempts to prevent so called 'active expiration against the ventilator'. Those engaged in this endeavour would, I think, do well to reflect on whether they have actually shown 'active' expiration in their infants.

Greenough et $a l^{2}$ and subsequent investigators ${ }^{13}$ have shown that in some infants making spontaneous respiratory efforts a period of expiratory flow may be observed during a portion of the inspiratory phase of mechanical ventilation. That this reflects an active expiratory effort is an assumption for which little support can be found in any of these authors' publications. I suggest that they have on the contrary observed no more than a form of synchrony between infant and ventilator.

During mechanical ventilation the force determining lung inflation is the transpulmonary pressure - that is, the difference between the positive pressure applied to the airway and the pressure in the pleural space. If during the inspiratory phase of mechanical ventilation the infant makes an inspiratory effort pleural pressure must become more negative, increasing transpulmonary pressure and therefore lung volume. Should the infant then relax while the ventilator inspiratory phase continues, transpulmonary pressure and lung volume must fall and expiratory flow must occur. No active expiratory effort is required from the infant.

Indeed, careful examination of Greenough's published recordings of 'active expiration' ${ }^{2}$ reveals that the expiratory flow was not associated with any rise in oesophageal pressure above baseline, a finding incompatible with an active expiratory effort. On the two occasions when expiratory flow occurred during the inspiratory phase of the ventilator, however, this flow was immediately preceded by synchronous inspiratory effort.

The only prerequisite for this pattern of expiratory flow is that the inspiratory phase of the ventilator should last longer than the infant's own inspiratory effort. It comes as no surprise, therefore, that Field et al could make this pattern disappear by increasing rate or decreasing inspiratory:expiratory ratio, both strategies decreasing the inspiratory time of the ventilator. They claim to have converted active expiration into synchrony; I would suggest that they had synchrony throughout. (Unfortunately, these authors published no relevant recordings.)

Regardless of the mechanism of this expiratory flow, Greenough et al have convincingly shown it to be strongly associated with pneumothorax. If it is correct to assume that pneumothorax is the result of overdistension of some part of the lung it is intuitively hard to see why an active expiratory effort should put the infant at greatest risk. By decreasing transpulmonary pressure such a response should limit lung inflation. On the other hand, it is easy to imagine that intermittent synchronous breaths might be exposing the lung to occasional excessive transpulmonary pressures predispose to pneumothorax.

The search for ways of achieving 'synchrony' between infant and ventilator should proceed with caution; intermittent synchrony may be much the most dangerous pattern of interaction (as I believe Greenough has shown though misinterpreted). It is unforunate that at present the search seems to be directed at preventing what is no more than passive expiration. Greenough, South and Morley, and Field et al seem to be in agreement that further investigation of spontaneous respiratory activity is necessary; can I suggest that as a first step they examine the electromyogram signal of the abdominal wall before deciding what is active and what is not?

\section{ANDREW RAMSDEN University College, London WC1}

\section{Drs Field and Milner comment:}

We were very interested in the comments of Dr Ramsden and agree that simultaneous abdominal wall electromyogram signals would be useful in resolving this controversy. We would like to make two points in reply.

Firstly, we have no doubt that neonates can and quite frequently do make active expiratory efforts while receiving mechanical ventilation. May we refer Dr Ramsden to the Figure in our paper. ${ }^{1}$ In this he will see from the oesophageal pressure trace that the baby is making vigorous respiratory efforts, which are raising the positive end expiratory pressure within the endotracheal tube by over $5 \mathrm{~cm}$ of water and raising the peak inspiratory pressure by a similar amount when the active respiratory effort coincides with the inflation phase of the ventilator's cycle.

Secondly, we have consistently found that converting the baby from active expiration into synchrony leads to an increase in the tidal volume. We feel that this finding is not compatible with Dr Ramsden's hypothesis.

\section{Dr Greenough comments:}

We thank Dr Ramsden for his comments. He is certainly correct to point out the association of ventilator inflation occurring at end inspiration in our paper. ${ }^{2}$ We would, however, prefer not to describe this association as 'synchrony' as we have previously used this term to describe a very particular interaction - that is, the commencement of ventilator inflation occurring with early inspiration. ${ }^{4}$ Neither this nor Head's paradoxical reflex (provoked augmented inspiration), both inspiratory efforts occurring 
during ventilator inflation, lead to the development of a pneumothorax. In fact, both are beneficial, the former improving blood gases ${ }^{5}$ and the latter resulting in increased compliance. ${ }^{6}$ The 'active expiratory reflex' rather describes the interaction when ventilator inflation occurs only within a respiratory window at end inspiration. ${ }^{7}$ This combination does of course generate the largest transpulmonary pressure swings and hence by alveolar overdistension could cause rupture. Whether the succeeding expiratory effort is, however, active or passive remains controversial, the magnitude of oesophageal pressure swing may be inaccurate in infants with respiratory distress syndrome, ${ }^{8}$ and only electromyogram recordings will conclusively answer this but until recently have technically not been feasible. Our research is not directed at trying to prevent passive expiration but rather at reducing the incidence of pneumothoraces among other complications, and it seems likely that if ventilator inflation could be directed outside the 'respiratory window' we have described ${ }^{7}$ this may be possible. Fast rates are not always successful;' the answer seems more complex than simply reducing the inspiratory expiratory ratio or increasing the rate-hence we emphasise the necessity for further investigation of spontaneous respiratory activity during ventilator inflation and a greater understanding of the interaction of the two.

\section{References}

${ }^{1}$ Field D, Milner A, Hopkin I. Manipulation of ventilator settings to prevent active expiration against positive pressure inflation. Arch Dis Child 1985;60:1036-40.

2 Greenough A, Wood S, Morley CJ, Davis JA. Pancuronium prevents pneumothoraces in ventilated premature babies who actively expire against positive pressure ventilation. Lancet 1984;i:1-3.

${ }^{3}$ South M, Morley CJ. Monitoring spontaneous respiration in the ventilated neonate. Arch Dis Child 1986;61:291-4.

4 Greenough A, Morley CJ, Davis JA. Interaction of spontaneous respiration with artificial ventilation in preterm babies. J Pediatr 1983;103:769-73.

${ }^{5}$ Greenough A, Pool J, Greenall F, Morley CJ, Gamsu H. Spontaneously breathing ventilated infants have improved oxygenation at fast rates. $J$ Pediatr. (Submitted.)

${ }^{6}$ Greenough A, Elias-Jones AC, Pool J, Morley CJ, Davis JA. The therapeutic actions of theophylline in preterm ventilated infants. Early Hum Dev 1985;12:15-22.

${ }^{7}$ Greenough A, Morley CJ, Johnson P. Active expiratory reflex in preterm ventilated infants. In: Jones $C$, Nathanelsz $P$, eds. The physiological development of the newborn. 1985:259.

${ }^{8}$ Le Soucf PN, Lopes JM, England SJ, Bryan MH, Bryan AC. Influence of chest wall distortion on oesophageal pressure. J Appl Physiol 1983:55:353-8.

9 Greenough A, Morley CJ, Pool J. Active expiration - are fast rates an effective alternative to paralysis? Early Hum Dev (In press.)

\section{Choice of feeding preparations for the newborn}

Sir,

As a paediatric dietitian I read with interest Dr Bamford's comments on the choice of feeding preparations for the newborn. ${ }^{1}$ The choice of a modified baby milk is, as he points out, virtually an impossible choice as all comply with the guidelines of the Department of Health and Social Security.

In my view the solution is for a shared contract. An agreement could be made with the baby food manufacturers to supply their appropriate baby milk formulas at an acceptable set price to maternity units, children's hospitals, and paediatric units. (Such a contract has been accepted unofficially in the past and is likely to be formally accepted if supported by paediatricians.) This would do away with 'doubtful incentives' and might encourage the baby food manufacturers, who no longer have to compete for business, to donate a portion of their shared profits to paediatric research!

If breast feeding, for whatever reason, is not undertaken then the choice of baby milk, from the low solute range, should be made by the mother, particularly if she is distressed at being unable to breast feed. There is a clear variation in cost, which is of major importance for many families. If determined mothers are forced to feed their infants on a product they may, on discharge from hospital, change the formula, which could unsettle the infant.

We must be open minded and supply a choice of formulas that meet the requirements of young infants. More importantly, we must show we are unbiased. Supplying only one brand of baby milk formula is misleading as it implies to the general public that a particular health authority considers this product to be the best infant formula available. That the decision has been made only for financial reasons is not obvious and it allows the selected food manufacturer to use the contract award for sales promotion.

The undesirability of relying on one baby milk formula was emphasised recently when one powder was condemned as a suspected source of salmonella and immediately withdrawn. Had the ready to feed milk been affected, units solely using the brand in question would not have been able to offer an alternative. The fact that the incident happened in the Christmas period intensified the problem.

Expert opinion on the finer differences in baby milk formulas is available from paediatric dietitians, who are always pleased to advise.

Christine Clothier Royal Liverpool Children's Hospital, Alder Hey,

Liverpool L12 $2 A P$

Sir,

The seductive blandishments of the milk food industry described by Dr Bamford ${ }^{1}$ have been avoided in at least one hospital for six years. Here, midwives and doctors recite 'all baby milks approved by the Department of Health and Social Security are suitable. If you have a particular milk which you wish to use, we will try to provide it during your baby's stay in hospital.' A recent and unexpected bonus was the absence of organisational problems when Osterfeed was suddenly withdrawn.

Product endorsement by hospitals is actively sought by infant food manufacturers, and perhaps to a greater degree than many paediatricians are aware. The ready to feed 